\title{
mTORC2 Regulates Lipogenic Gene Expression through PPAR $\gamma$ to Control Lipid Synthesis in Bovine Mammary Epithelial Cells
}

\author{
Zhixin Guo $\mathbb{D}^{1},{ }^{1}$ Keyu Zhao ${ }^{D},{ }^{1}$ Xue Feng $\mathbb{D}$, , Dandan Yan $\left(\mathbb{D},{ }^{1}\right.$ Ruiyuan Yao $\mathbb{D}$, \\ Yuhao Chen, ${ }^{1,2}$ Lili Bao $\mathbb{i}^{1,3}$ and Zhigang Wang $\mathbb{1}^{1}$ \\ ${ }^{1}$ State Key Laboratory of Reproductive Regulation \& Breeding of Grassland Livestock, School of Life Sciences, Inner Mongolia University, \\ Hohhot 010021, China \\ ${ }^{2}$ School of Life Sciences, Jining Normal University, Jining 012000, China \\ ${ }^{3}$ School of Basic Medical Science, Inner Mongolia Medical University, Hohhot 010110, China
}

Correspondence should be addressed to Lili Bao; baolili1203@126.com and Zhigang Wang; lswzg@imu.edu.cn

Received 2 January 2019; Revised 2 April 2019; Accepted 23 April 2019; Published 16 May 2019

Academic Editor: Shoichiro Ono

Copyright (C) 2019 Zhixin Guo et al. This is an open access article distributed under the Creative Commons Attribution License, which permits unrestricted use, distribution, and reproduction in any medium, provided the original work is properly cited.

\begin{abstract}
The mechanistic target of rapamycin complex 2 (mTORC2) primarily functions as an effector of insulin/PI3K signaling to regulate cell proliferation and is associated with cell metabolism. However, the function of mTORC2 in lipid metabolism is not well understood. In the present study, mTORC2 was inactivated by the ATP-competitive mTOR inhibitor AZD8055 or shRNA targeting RICTOR in primary bovine mammary epithelial cells (pBMECs). MTT assay was performed to examine the effect of AZD8055 on cell proliferation. ELISA assay and GC-MS analysis were used to determine the content of lipid. The mRNA and protein expression levels were investigated by RT/real-time PCR and western blot analysis, respectively. We found that cell proliferation, mTORC2 activation, and lipid secretion were inhibited by AZD8055. RICTOR was knocked down and mTORC2 activation was specifically attenuated by the shRNA. Compared to control cells, the expression of the transcription factor gene PPARG and the lipogenic genes LPIN1, DGAT1, ACACA, and FASN was downregulated in RICTOR silencing cells. As a result, the content of intracellular triacylglycerol (TAG), palmitic acid (PA), docosahexaenoic acid (DHA), and other 16 types of fatty acid was decreased in the treated cells; the accumulation of TAG, PA, and DHA in cell culture medium was also reduced. Overall, mTORC2 plays a critical role in regulating lipogenic gene expression, lipid synthesis, and secretion in pBMECs, and this process probably is through PPAR $\gamma$. This finding provides a model by which lipogenesis is regulated in pBMECs.
\end{abstract}

\section{Introduction}

The solid matter of milk from dairy cows is composed primarily of proteins, fat, and lactose. Milk fat is the most variable component of milk-95\% to $98 \%$ of which is triacylglycerol (TAG), with the remainder comprising other lipids $[1,2]$. A complex network of proteins controls milk synthesis with mTOR (mechanistic target of rapamycin) functioning as a central regulator, and milk fat synthesis appears to be governed, at least in bovines, by an interactive network between $\operatorname{PPAR} \gamma$ and other transcription factors [3]. A transcriptomewide analysis has revealed that the PPAR $\gamma$-coding gene $P P A R G$ is critical in milk fatty acid metabolism in goat mammary epithelial cells [4].
Numbers of the peroxisome proliferator-activated receptors (PPARs) family, such as PPAR $\gamma, \operatorname{PPAR} \alpha$, and PPAR $\beta / \delta$, are a group of lipogenesis-related transcription factors and are critical in lipid metabolism during lactation-particularly, the PPAR $\gamma$ network, which controls milk fat synthesis in lactating ruminants [5]. In the last 20 years, PPAR $\gamma$ has been studied extensively in monogastrics and ruminants and is pivotal in controlling lipid metabolism $[3,5]$. PPAR $\gamma$ is activated by several long-chain fatty acids or the PPAR $\gamma$ agonist, along with upregulating such target genes as DGAT1 and LPIN1 [5, 6], which encode important enzymes in fatty acid esterification and TAG synthesis $[7,8]$, and FASN and ACACA $[5,6]$, which encode key enzymes to catalyze the synthesis of fatty acids [9]. The genes for the enzymes are 
overexpressed in Holstein dairy cows during lactation and promote milk fat synthesis and secretion [10].

mTOR combines with various components to form two mTOR complexes, mTORC1 and mTORC2, and integrates nutritional signals, growth factors, and energy status to regulate protein synthesis, cell growth, and metabolism [11]. mTORC1 (RAPTOR) is a central regulator of cell metabolism and is sufficient for the accumulation of triglycerides and de novo fatty acid biosynthesis [12-14], whereas the function of mTORC2 (RICTOR) in lipid metabolism is not well understood.

The most important achievement of studies on mTORC2 is likely the role in phosphorylation and activation of AKT/ $\mathrm{PKB}$, a key effector of insulin and growth factor signaling [11, $15,16]$. Recent findings have demonstrated a novel function of mTORC2 in regulating another group of lipogenesis-related transcription factors, sterol regulatory element-binding proteins 1 (SREBP1) $[17,18]$, but the function of mTORC2 on PPAR $\gamma$ activation is not clear. Nevertheless, the regulatory function of mTORC2 on lipogenic gene expression via PPAR $\gamma$ and the accumulation of triacylglycerol and fatty acids both extracellular and intracellular are unknown.

The purpose of this study was to determine the functions and mechanisms of mTORC2 in lipid biosynthesis and secretion by measuring the expression of PPARG and the lipogenic genes LPIN1, DGAT1, ACACA, and FASN in pBMECs. We propose a regulatory model of milk fat synthesis and secretion in bovine mammary epithelial cells, in which mTORC2 regulates lipogenic gene expression and milk lipid synthesis through PPAR $\gamma$. The results of this study provide insights into the precise mechanism by which lipid synthesis and secretion are regulated in mammary epithelial cells.

\section{Materials and Methods}

2.1. Primary Bovine Mammary Epithelial Cells Cultures. All animals and procedures used in this study were conducted according to the guidelines for the care and use of experimental animals established by the Inner Mongolia University Animal Care and Use Committee. Mammary tissues were obtained from 3 Chinese Holstein cows after being slaughtered in a commercial cattle slaughter farm. The primary bovine mammary epithelial cells (pBMECs) were isolated and cultured by the adherent culture of small-sized cow mammary tissues. After mammary tissues were surgically removed from the slaughtered cow, they were placed in sterile, ice-cold phosphate-buffered saline (PBS) that was supplemented with $300 \mathrm{U} / \mathrm{mL}$ penicillin $\mathrm{G}$ and $100 \mathrm{mg} / \mathrm{mL}$ streptomycin (V900929, Sigma-Aldrich, Inc. St. Louis, MO, USA) and transported immediately to the laboratory. The mammary tissues were trimmed of visible fat and connective tissue and washed with PBS several times until the solution became pellucid and devoid of milk. Then, the mammary tissues were cut into small pieces (approx. $1 \times 1 \times 1 \mathrm{~mm}^{3}$ ) and established as a primary culture, from which bovine mammary epithelial cells (BMECs) were isolated and cultured, and cell morphology was examined by light microscopy. Purified primary BMECs were maintained and incubated in DMEM/F12 media (SH30023.01, Hyclone Laboratories, Inc.
Logan, UT, USA) that contained $10 \%$ fetal bovine serum ( 04 001-1ACS, Biological Industries, Israel) and supplemented with $5 \mu \mathrm{g} / \mathrm{ml}$ insulin (I6634, Sigma-Aldrich, Inc. St. Louis, MO, USA), $10 \mathrm{ng} / \mathrm{ml}$ epidermal growth factor (EGF, E4127, Sigma-Aldrich, Inc. St. Louis, MO, USA), $1 \mu \mathrm{g} / \mathrm{ml}$ hydrocortisone (G8450, Solarbio Life Sciences, Beijing, China), and $1 \mu \mathrm{g} / \mathrm{ml}$ progesterone (V900699, Sigma-Aldrich, Inc. St. Louis, MO, USA) in a $25 \mathrm{~cm}^{2}$ tissue culture flask at $37^{\circ} \mathrm{C}$ in humidified air with $5 \% \mathrm{CO}_{2}$ as described $[19,20]$. The expression of KRT8 (keratin 8), KRT18 (keratin 18), and CSN2 (casein beta) was examined by RT-PCR with the primers (Table S1); the proteins of KRT7 (keratin 7), KRT18 (keratin 18), and CSN2 were examined by immunofluorescence. $\mathrm{P}_{2}$ to $\mathrm{P}_{4}$ primary bovine mammary epithelial cells (pBMECs) that were in the logarithmic growth phase were used to all experimental assays. The bovine mammary fibroblasts were also isolated and cultured by the adherent culture of small-sized cow mammary tissue, and the purified bovine mammary fibroblasts were used as negative control cells for detecting CSN2 and VIM (vimentin) by RT-PCR with the primers (Table S1) and examination of CSN2 and VIM (vimentin) by immunofluorescence.

2.2. Reagents and Antibodies. AZD8055, an ATP-competitive mTOR inhibitor, was purchased from Selleck Chemicals (S1555, Selleck Chemicals, 9330 Kirby Drive, STE 200m Houston, TX 77054, USA) and dissolved in DMSO (D2650, Sigma-Aldrich, Inc. St. Louis, MO, USA). The stock concentration is $10 \mathrm{mM}$. The proportion of DMSO in the cell culture medium is less than $0.5 \%(\mathrm{v} / \mathrm{v})$ in any experiment.

The following primary antibodies were used in this study: anti-p-S6 (Ser240/244, \#5346s), anti-AKT (\#9272), antiACC (\#3662), anti-p-AKT (Ser473, \#9271s), anti-p-4EBP1 (Thr37/46, \#2855s) (Cell Signaling Technology, Inc., Beverley, MA, USA); anti-S6 (ab184551), anti-4EBP1 (ab2606), anti-PPAR $\gamma$ (ab45036), anti-LPIN1 (ab70138), anti-p-mTOR (Ser2448, ab32028), anti-mTOR (ab10926), anti-DGAT1 (ab100982), anti-RICTOR (ab105479), anti-FAS (ab22759) (Abcam, plc 330 Cambridge Science Park, Cambridge, UK); anti- $\beta$-actin (A5441, Sigma-Aldrich, Inc. St. Louis, MO, USA); ECL Anti-Rabbit IgG-HRP (NA934-100 $\mu \mathrm{l}$ ) and ECL Anti-Mouse IgG-HRP (NA931-100 $\mu$ l) (GE Healthcare, Little Chalfont, Buckinghamshire, UK).

2.3. MTT Assay. Procedures were performed as we described before [21]. Briefly, exponentially growing pBMECs were seeded into 96 -well plates at $6 \times 10^{3}$ cells per well $24 \mathrm{~h}$ before drug treatment. Then cells were treated with AZD8055 at various concentrations (1.5625 nM, $3.125 \mathrm{nM}, 6.25 \mathrm{nM}, 12.5$ $\mathrm{nM}, 25 \mathrm{nM}, 50 \mathrm{nM}, 100 \mathrm{nM}$, and $200 \mathrm{nM}$ ) for $12 \mathrm{~h}$ and $24 \mathrm{~h}$. MTT absorbance was measured with a spectrophotometer set (Thermo, Multiskan SX 353, USA) to evaluate the inhibitory efficiency of inhibitor on cell proliferation.

2.4. DNA Construct and In Vitro Transfection. A short hairpin RNA (shRNA) ( $5^{\prime}$-aaGTACAGAATTGCTACTAGGTTCAAGAGACCTAGTAGCAATTCTGTACtt-3') that harbored the siRNA that targets RICTOR was designed based on the sequence of bovine RICTOR gene (NM_001144096.3). 
TABLE 1: The target genes and primers for qPCR.

\begin{tabular}{|c|c|}
\hline Gene Name & Primer sequence $\left(5^{\prime} \longrightarrow 3^{\prime}\right)$ \\
\hline \multirow{2}{*}{ RICTOR (NM_001144096.3) } & P1:CCCGACAGTATGTACGAGC \\
\hline & P2: ATCCCAGAGTTTCCAGGTT \\
\hline \multirow{2}{*}{ PPARG (NM_181024.2) } & P1:GACGGGAAAGACGACAGACAAATC \\
\hline & P2: CGTTCAAGTCAAGGTTCACAAAG \\
\hline \multirow{2}{*}{ DGAT1 (XM_025001413.1) } & P1:AAGCCCTTCAAGGACATG \\
\hline & P2:GCAGTAGAAGAAGATGAGCC \\
\hline \multirow{2}{*}{ LPIN1 (NM_001206156.2) } & P1:AAAGTGAGCCAAAACGGGT \\
\hline & P2:TTCTTTTCGATCACTTCCCTG \\
\hline \multirow{2}{*}{ ACACA (NM_174224.2) } & P1:ATCCCACGCATCTATGTAG \\
\hline & P2:AGCACTGACTCTCTTGTAATC \\
\hline \multirow{2}{*}{ FASN (NM_001012669.1) } & P1:GGACGCTTTCCGTTACAT \\
\hline & P2:CCAGTGATGATGTAGCTCTTG \\
\hline \multirow{2}{*}{ ACTB (NM_173979.3) } & P1:CACCACGGCCGAGCGGGAAATC \\
\hline & P2:AGAGCCTCAGGGCAGCGGAACC \\
\hline
\end{tabular}

A double-stranded DNA fragment was generated by chemical synthesis, encoding the RICTOR-shRNA with a BamHI restriction site at the $5^{\prime}$ end and a HindIII restriction site at the $3^{\prime}$ end. The DNA fragment was inserted into the multiple cloning site of pRNAT-U6.1/Neo plasmid, which is a GenScript siRNA expression vector (Cat. No. SD1211, GenScript Biotech Corp, Nanjing, China), to yield pRNAT-U6.1/Neo-RICTOR-shRNA. The plasmid pRNATU6.1/Neo-shRICTOR was transfected into primary BMECs using Lipofectamine TM2000 (11668019, Invitrogen, Carlsbad, New Mexico, USA) per the manufacturer's instructions. Transfected cells were selected with G418 (SV30068.02, Hyclone Laboratories, Inc. Logan, Utah, USA) for $48 \mathrm{~h}$ and imaged under a digital fluorescence microscope (Carl Zeiss Microscopy, LLC One Zeiss Drive, Thornwood, NY 10594, USA), and then cell culture medium and cells were separated and collected, respectively.

2.5. ELISA. ELISA was used to detect the concentration of triacylglycerol (TAG), palmitic acid (PA), and docosahexaenoic acid (DHA) as previously described [21]. Primary BMECs were seeded into 6 -well plates at $8 \times 10^{5}$ cells per well, incubated until $80 \%$ confluence. For the inhibitor experiments, cells were treated with $100 \mathrm{nM}$ AZD8055 for 12 $\mathrm{h}$ or $24 \mathrm{~h}$; for the RICTOR knocking down experiments, cells were transfected with pRNAT-U6.1/Neo-shRICTOR and the transfected cells were selected with G418 for $48 \mathrm{~h}$. Cell culture medium was collected for measurement of extracellular TAG, PA, and DHA. Control and treated primary BMECs were harvested with trypsin and were centrifuged to remove supernatants, and then cell lysates were prepared. Equal volume of protein lysates was measured for TAG, PA, and DHA by ELISA. All measurements were made in triplicate, and the mean values of at least 3 repeat experiments were used for the statistical analysis.

2.6. Western Blot Analysis. Western blot was used to detect the expression of indicated proteins and phosphorylated proteins as previously described [22]. Briefly, control and treated primary BMECs were harvested with trypsin and lysed in cell lysis buffer. Equal amounts $(40 \mu \mathrm{g})$ of protein were electrophoresed, and transferred to polyvinylidene fluoride membranes, and incubated with the primary antibody. Peroxidase-conjugated secondary antibody and enhanced chemiluminescence (ECL) reagent were used to detect the signals with the Western Blotting System.

2.7. qPCR Analysis. The quantitative real-time polymerase chain reaction (qPCR) was performed according to Guo and Wang [20] with some modifications. RT-qPCR was used to determine the mRNA abundance of PPARG, DGAT1, LPIN1, $A C A C A, F A S N$, and RICTOR in the primary BMECs of the treatment groups and control. Cells were transfected with pRNAT-U6.1/Neo-shRICTOR and the transfected cells were selected with G418 for $48 \mathrm{~h}$. Total RNA was isolated from the untreated and treated cells using RNAzol (9109, TaKaRa Co. Ltd., Dalian, China), following the manufacturer's instructions. RNA quantities over $600 \mathrm{ng} / \mu \mathrm{L}$ and a purity of $1.90 \sim 2.0$ by as 260/280 ratio 1.90 2.0 were used to synthesize cDNA. The RNA integrity was assessed by electrophoresis.

Total RNA was reverse-transcribed with an oligo $(\mathrm{dT})_{12-18}$ primer using the EasyScript ${ }^{\circledR}$ One-Step gDNA Removal and cDNA Synthesis SuperMix Kit (AE311, TransGen Biotech Co. Ltd., Beijing, China), and gDNA was removed. cDNA sequences were amplified with the primers shown in Table 1. GAPDH, RPS15A, PPIA, ACTB, and $B 2 M$ were tested as internal control genes, and $A C T B$ was selected as the best internal control gene (Table S2), according to available NormFinder and the stability values [23]. The target genes that were selected for evaluation in RNA samples from control and treated cells were related to lipid synthesis (i.e., PPARG, DGAT1, LPIN1, ACACA, and FASN) (Table 1). All primer pairs were designed with Primer Premier Software (PREMIER Biosoft) and confirmed using Primer-BLAST (NCBI) online. The presence of a single product and the absence of primer dimers were verified by agarose gel electrophoresis.

The reactions were run using the KAPA SYBP ${ }^{\circledR}$ FAST qPCR Kit Optimized for LightCycler ${ }^{\circledR} 480$ (KM4110, KAPA 


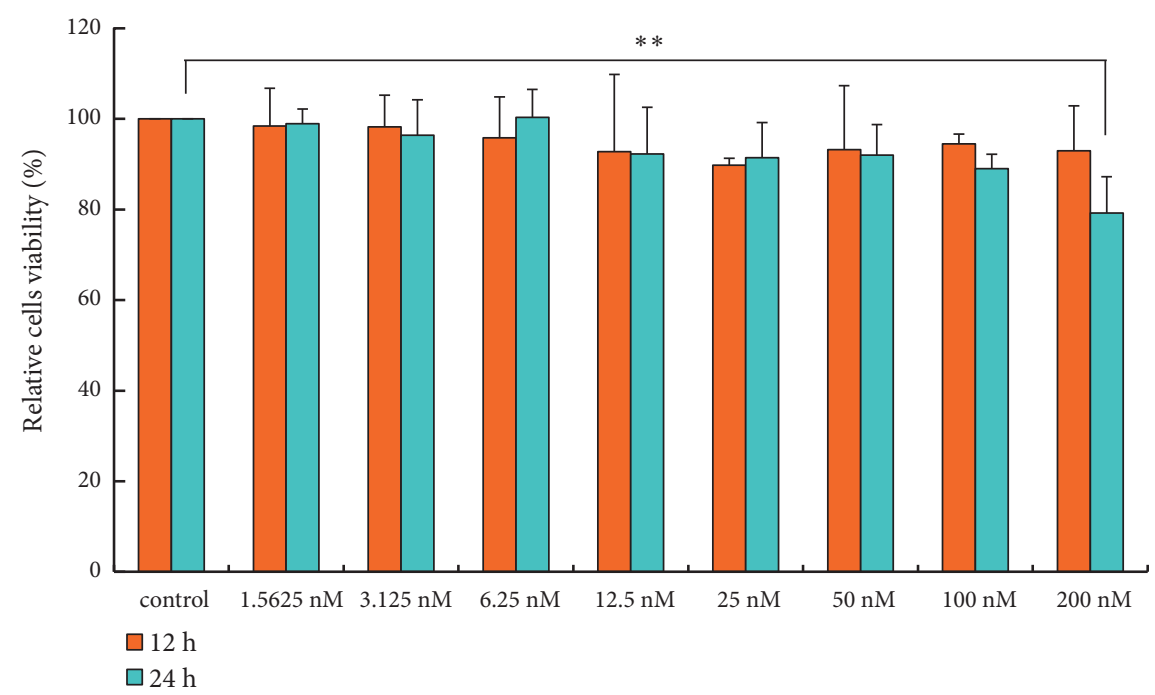

FIGURE 1: AZD8055 inhibits cell proliferation of primary bovine mammary epithelial cells (pBMECs). AZD8055 inhibits cell proliferation of pBMECs when its concentration is $200 \mathrm{nM}$ for $24 \mathrm{~h}$. $p=0.001, * p<0.01 ; \mathrm{n}=3$ biological replicates. Error bars indicate SD.

BIOSYSTEMS, Inc., Boston, Massachusetts, USA) according to the manufacturer's instructions. Three technical replicates were run. $2^{-\Delta \Delta C T}$ values were calculated to determine expression levels, and the qPCR results were analyzed by Student's ttest to compare the expression between untreated and treated groups. 3 independent experiments were performed.

2.8. Gas Chromatography and Mass Spectrum. Cells were transfected with pRNAT-U6.1/Neo-RICTOR-shRNA and the transfected cells were selected with G418 for $48 \mathrm{~h}$. Untreated and treated cells were collected and dissolved in $1 \mathrm{~mL}$ lysis buffer. Fatty acid methyl esters (FAME) were extracted twice with $\mathrm{n}$-hexane at room temperature and evaporated to dryness at $30^{\circ} \mathrm{C}$ for $30 \mathrm{~min}$, then dissolved in n-hexane, and then separated in a gas chromatography-mass spectrum (Shimadzu, GCMS-QP2010 ultra, Shimadzu, Japan) using an Agilent HP-88 capillary-column $(100 \mathrm{~m} \times 0.25 \mathrm{~mm} \times$ $0.20 \mu \mathrm{m}$, Agilent Technologies, Santa Clara, CA, USA). The program was set to column temperature $60^{\circ} \mathrm{C}$ for $1 \mathrm{~min}$, with ramping of $40^{\circ} \mathrm{C} / \mathrm{min}$ up to $140^{\circ} \mathrm{C}$, and a hold for 10 min, $4^{\circ} \mathrm{C} / \mathrm{min}$ up to $240^{\circ} \mathrm{C}$, and a hold for $15 \mathrm{~min}$. The injector temperature was $220^{\circ} \mathrm{C}$, and the sample was $1 \mu \mathrm{L}$. The injection mode was split flow. External standards were obtained from Sigma-Aldrich (Cat. No.18919-1AMP).

2.9. Statistical Analyses. Data are presented as mean \pm SD. Statistical significance for the dose effect was determined by a general linear model, the percentage of fatty acid was determined by chi-square, and other data were determined by one-way ANOVA, followed by Tukey's method. Statistical analyses were conducted using SPSS PASW Statistics for Windows, v18.0 (SPSS Inc.: Chicago, IL, USA). The western blot results were quantified on a Gel-Pro Analyzer 4.0 (Media Cybernetics, USA). The results were presented as the average of at least 3 biological replicates. $p \leq 0.05$ was considered to be statistically significant.

\section{Results}

3.1. AZD8055 Inhibits Proliferation of pBMECs. Primary bovine mammary epithelial cells (pBMECs) were isolated by the adherent culture of small-sized cow mammary tissues, and their morphology was of a typical epithelial cell. The biomarker genes KRT18, KRT8, and CSN2 were transcribed, and the biomarker proteins KRT7, KRT18, and CSN2 were expressed in pBMECs, whereas the biomarker gene CSN2 and protein CSN2 were not expressed in the negative control cells, bovine mammary fibroblasts (Figure $\mathrm{S} 1$ ).

AZD8055, an ATP-competitive mTOR inhibitor, prevents the phosphorylation of mTOR and then suppresses mTORC1 and mTORC2 simultaneously, and inhibits the phosphorylation of mTORC1 substrates S6 and 4E-BP1 as well as phosphorylation of the mTORC2 substrate AKT [24]. To ensure that the lipid levels in the culture medium were not affected by the difference in cell number between the control and treatment groups, we first confirmed that the inhibitor concentration and incubation time had no significant effect on cell number. We determined the effects of AZD8055 on pBMEC proliferation by MTT assay and observed that it inhibited cell proliferation at a concentration of $200 \mathrm{nM}$ for $24 \mathrm{~h}$ (Figure 1) $(p<0.05)$. Thus, we treated cells for $24 \mathrm{~h}$ with $100 \mathrm{nM}$ AZD8055 in the subsequent experiments.

3.2. AZD8055 Attenuates Accumulation of Lipids in the Culture Medium and the Activation of mTORC1 and mTORC2 in pBMECs. To determine the effects of AZD8055 on lipid secretion, we treated pBMECs with $100 \mathrm{nM}$ AZD8055 for $24 \mathrm{~h}$, and the content of TAG, PA, and DHA in the culture medium was determined. The results showed that AZD8055 inhibited the secretion of TAG, PA, and DHA (Figure 2(a)) $(p<0.01)$. Further, we determined the activation of mTORC1 and mTORC2, and the results showed that the phosphorylation of S6 (Ser240/244) and 4EBP1 (Thr37/46) was inhibited (Figure 2(b)), indicating that $\mathrm{mTORCl}$ signaling was 

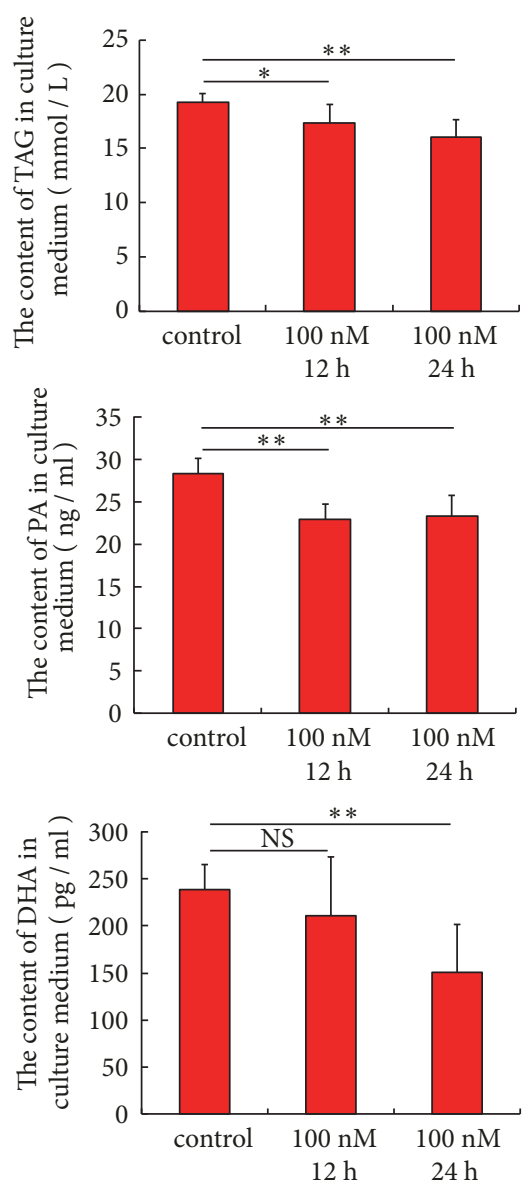

(a)

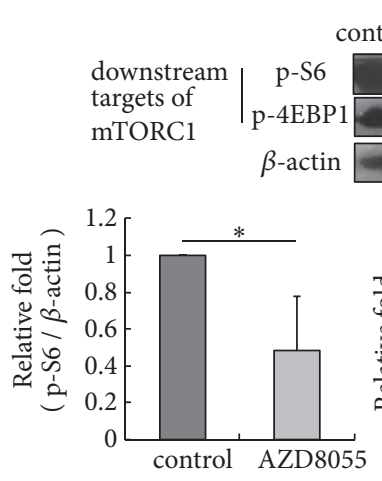

control AZD8055

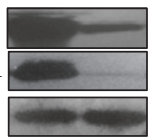

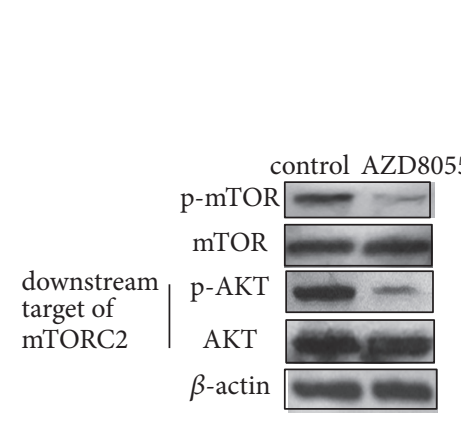

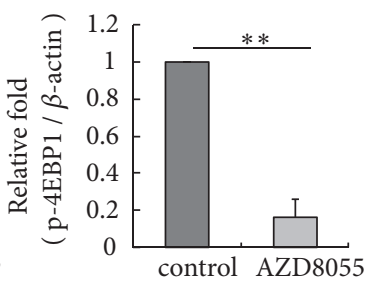

(b)
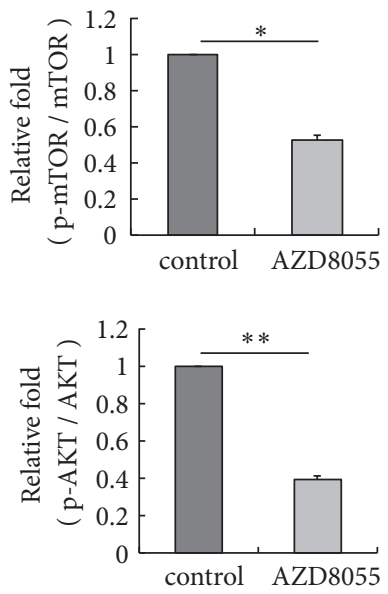

(c)

Figure 2: AZD8055 inhibits mTORC1 and mTORC2 activation simultaneously and decreases the accumulation of TAG, PA, and DHA in the culture medium. (a) Cells were treated with $100 \mathrm{nM} \mathrm{AZD8055}$ for $12 \mathrm{~h}$ or $24 \mathrm{~h}$ and the content of TAG $(p=0.031, \mathrm{p}=0.001), \mathrm{PA}(p=0.0001$, $p=0.0002$ ), and DHA ( $p=0.335, p=0.006$ ) was measured by ELISA. AZD8055 significantly decreased the accumulation of TAG, PA, and DHA in the culture medium. (b) AZD8055 attenuates the phosphorylation of downstream targets of mTORC1, including S6 (Ser240/244), and 4EBP1 (Thr37/46). (c) AZD8055 attenuates the phosphorylation of mTOR (Ser2448) and downstream target of mTORC2, AKT (Ser 473). $* p<0.05, * * p<0.01$, ns, no significantly; $\mathrm{n}=3$ biological replicates. Error bars indicate SD. 


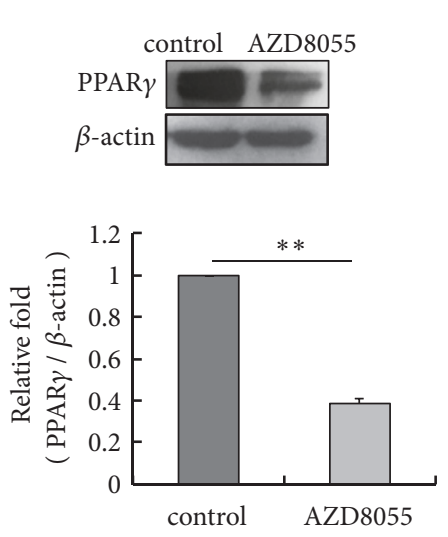

(a)
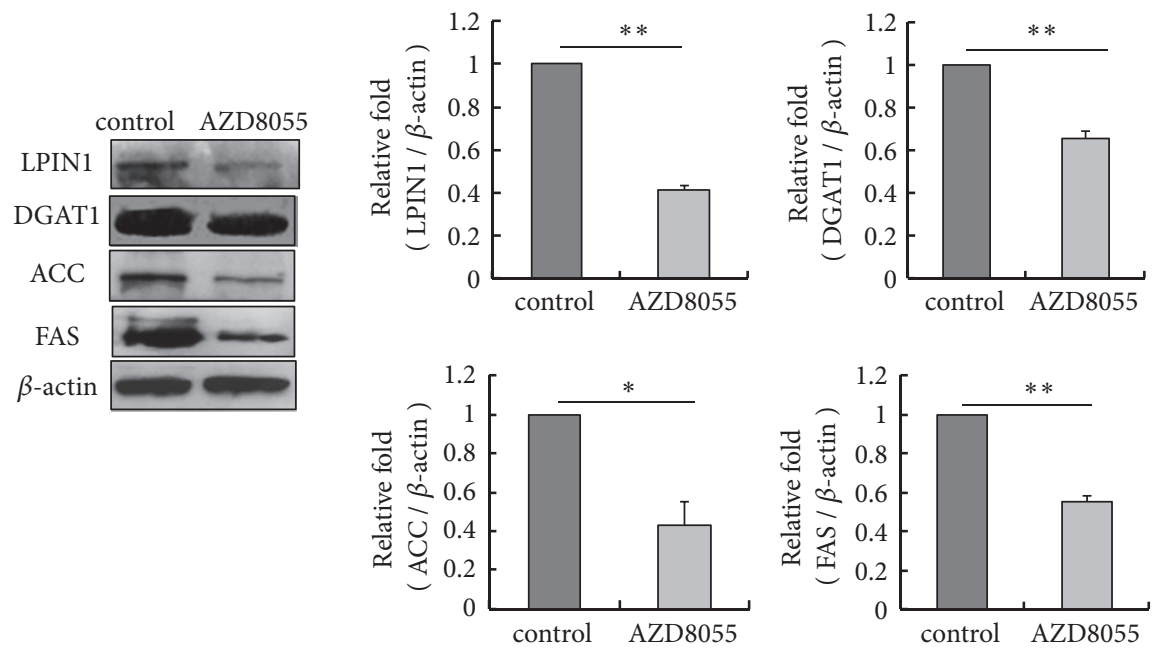

(b)

FIgure 3: AZD8055 inhibits the protein level of intracellular PPAR $\gamma$, LPIN1, DGAT1, ACC, and FAS in pBMECs. (a) The protein level of intracellular transcription factor PPAR $\gamma$ was inhibited by AZD8055. (b) The protein level of intracellular enzymes LPIN1, DGAT1, ACC, and FAS was inhibited by AZD8055. $* p<0.05, * * p<0.01, \mathrm{n}=3$ biological replicates. Error bars indicate SD.

impeded by AZD8055. Also, the phosphorylation of mTOR (Ser2448) and AKT (Ser 473), a direct substrate of mTORC2, was attenuated by the inhibitor (Figure 2(c)), suggesting that mTORC2 signaling is also inhibited by AZD8055. We concluded that AZD8055 attenuated secretion, and mTORC2 is associated with secretion and synthesis of lipid in pBMECs.

3.3. AZD8055 Decreases the Protein Level of Intracellular PPAR $\gamma$ and LPIN1, DGAT1, ACC, and FAS in PBMECs. The experiments above demonstrated that AZD8055 attenuates accumulation of TAG, PA, and DHA in the culture medium and the activation of MTORC1 and MTORC2; thus, we speculated that the expression of lipogenesis related transcription factor PPAR $\gamma$ and enzymes related to lipid synthesis is inhibited by AZD8055. We examined the level of intracellular PPAR $\gamma$, LPIN1, DGAT1, ACC, and FAS by western blot. The results showed that the protein level of intracellular PPAR $\gamma$ and these catalyzing enzymes was decreased by the inhibitor (Figures 3(a) and 3(b)), indicating mTORC2 is associated with the expression of transcription $P P A R G$ and the lipogenic genes.

3.4. Inactive mTORC2 Downregulates the Expression of PPARG and Lipogenic Genes in pBMECs. Now that the data above demonstrated that AZD8055 inhibited the mTORC2 activation and the protein level of intracellular transcription factor PPAR $\gamma$, and enzymes-LPIN1, DGAT1, ACC, and FAS in pBMECs, we have reason to speculate that the expression of LPIN1, DGAT1, ACACA, and FASN is regulated by mTORC2 via PPAR $\gamma$. To evaluate whether mTORC2 can regulate expression of PPARG and LPIN1, DGAT1, ACACA, and FASN, the degree of mTORC2 activation was reduced by knocking down RICTOR, a critical component of mTORC2, using targeting shRNA in pBMECs. The transfected cells were incubated with G418 supplementing insulin and EGF for 48 $\mathrm{h}$ and imaged (Figure S2). We first examined the mRNA and protein expression levels and found RICTOR was knocked down at both levels (Figures 4(a) and 4(b)). The activity of mTORC1 and mTORC2 was detected by western blot. The results showed that phosphorylation of mTOR (Ser2448) and AKT (Ser473) was attenuated in RICTOR silencing cells (Figure 4(c)) while mTORC1 activation was not affected (Figure 4(d)). These data indicate mTORC2 activation was specifically inhibited by targeting shRICTOR but not of mTORC1 in pBMECs.

Next, the mTORC2 signaling, which controls regulation of lipogenic gene expression via PPAR $\gamma$, was characterized. To this end, the mRNA levels of PPARG, LPIN1, DGAT1, $A C A C A$, and FASN were measured by RT-qPCR, and the corresponding proteins were detected by western blot in control and RICTOR silencing cells. Inactive mTORC2 significantly decreased PPARG expression in mRNA level (Figure 5(a)) $(p<0.05)$ and protein level (Figure 5(b)). Also, LPIN1, DGAT1, $A C A C A, F A S N$ mRNA abundances (Figure 5(c)) $(p<0.05)$ and intracellular protein levels (Figure 5(d)) were decreased. These data indicate that RICTOR silencing decreases the expression of these lipogenic genes, and this process probably is through $\operatorname{PPAR} \gamma$.

3.5. Inactive mTORC2 Inhibits the Synthesis and Secretion of Triacylglycerol and Fatty Acids in pBMECs. To confirm TAG and fatty acid synthesis and secretion are regulated by mTORC2 in pBMECs, we measured intracellular content and extracellular content in cell medium of TAG, PA, and DHA by ELISA. Comparing to control cells, the intracellular content of TAG, PA, and DHA was decreased (Figure 6(a)) $(p<0.01)$ in RICTOR silencing cells, and accumulation of these lipids in the culture medium was also significantly reduced (Figure 6(b)) $(p<0.05)$. Further, a total of 24 types of intracellular fatty acid were assayed by GC-MS-18 


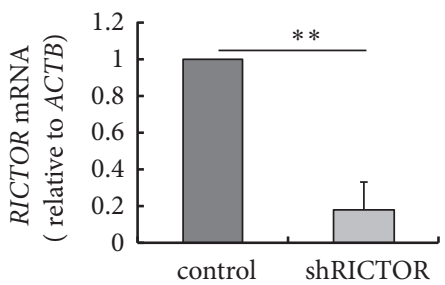

(a)

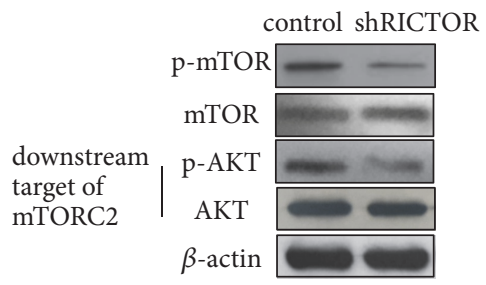

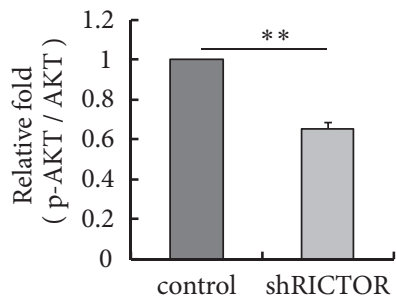

(c)

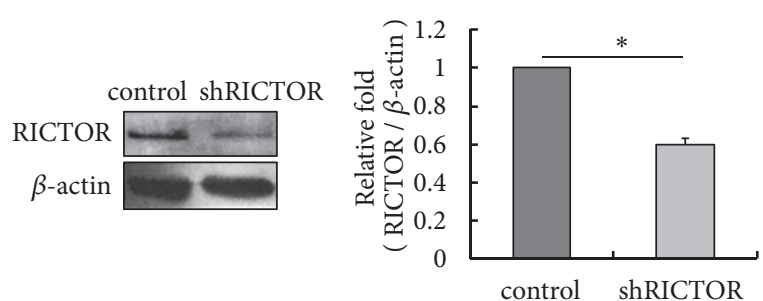

(b)

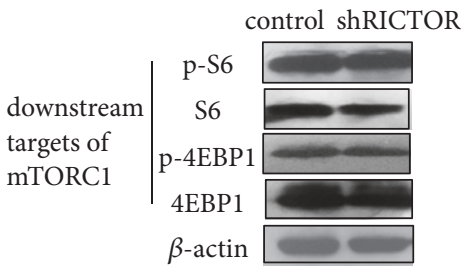

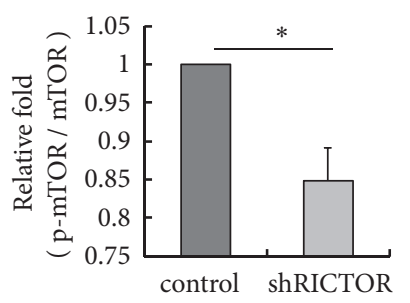
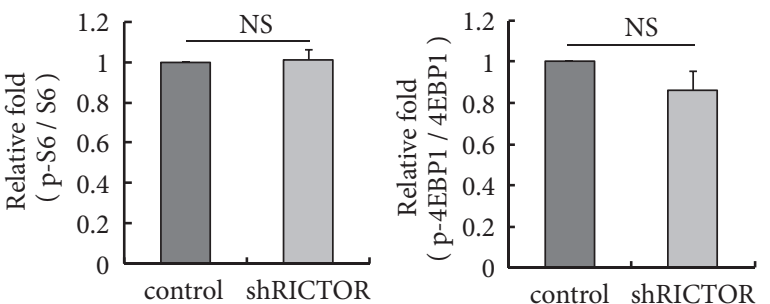

(d)

FIGURE 4: RICTOR silencing decreases mTORC2 activation but not mTORC1 in pBMECs. (a) RICTOR mRNA level is decreased in primary bovine mammary epithelial cells transfected with pRNAT-U6.1/Neo-RICTOR-shRNA ( $p=0.01)$. (b) RICTOR protein level is decreased in primary bovine mammary epithelial cells transfected with pRNAT-U6.1/Neo-RICTOR-shRNA. (c) RICTOR silencing attenuates the phosphorylation of mTOR (Ser2448) and downstream target of mTORC2, AKT (Ser 473). (d) RICTOR silencing does not attenuate the phosphorylation of downstream targets of mTORC1, including S6 (Ser240/244), and 4EBP1 (Thr37/46). $* p<0.05, * * p<0.01, \mathrm{~ns}, \mathrm{no}$ significantly; $\mathrm{n}=3$ biological replicates. Error bars indicate SD.

decreased, including PA and DHA, and 6 rose, and total content declined in RICTOR silencing cells (Table 2). These data indicate that synthesis and secretion of TAG and several types of fatty acid are governed by mTORC2 in pBMECs.

\section{Discussion}

mTORC2 function in lipogenesis through SREBP1 in response to insulin has been established [17, 25, 26], but it is unknown whether mTORC2 is involved in PPARG expression. In this study, we examined the function of mTORC2 in PPARG expression. We found that knockdown of RICTOR/ mTORC2 by shRNA downregulated PPARG expression and in turn decreased the expression of several lipogenic genes, including LPIN1, DGAT1, ACACA, and FASN. This finding implicates a novel function for mTORC2 which regulates the expression of lipogenic genes through PPAR $\gamma$ to govern lipogenesis in vitro.

It is essential for reliable RT-qPCR to be able to normalize the data using internal control genes [27]. According to the minimum information for publication of quantitative realtime PCR experiments (MIQE) guidelines, at least 2 internal control genes were needed, unless there is a strong proof that the single reference gene used is indeed not affected by the treatment and can be a valid normalizer. The optimal number and choice of reference genes must be experimentally determined [28]. In the present study, five internal control genes were experimentally examined, and $A C T B$ was selected as the best single internal control gene. The reference gene $A C T B$ is a valid normalizer and was used as single reference gene in studies of vertebrate gene expression [29]. However, it is critical to assess the reliability of the normalization by testing multiple internal control genes [27], and the use of one internal reference gene has potential limitations in normalization. Consequently, the possibility that RT-qPCR data may be poorly normalized should be recognized in our experiments.

Epithelial cells are the central component of mammary alveoli, which produce milk during lactation. A lactating ruminant mammary cell model is useful for the study of milk synthesis. In recent years, significant results have been obtained from bovine and goat mammary epithelial cells, including the function of $\mathrm{mTORCl}$ in cell proliferation, milk synthesis, and secretion [30-32] and that of lipogenesisrelated transcription factors and lipogenic genes in lipid biosynthesis [33-35]. But little has been reported on the regulatory function of mTORC2 with regard to lipogenic gene expression and the lipid synthesis in bovine mammary epithelial cells. In our study, we found that mTORC2 is 


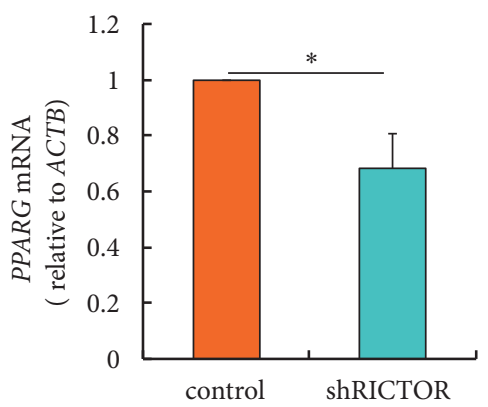

(a)

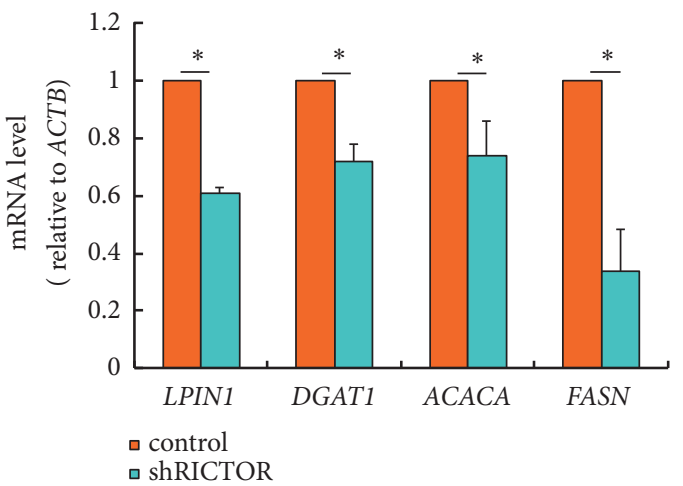

(c)
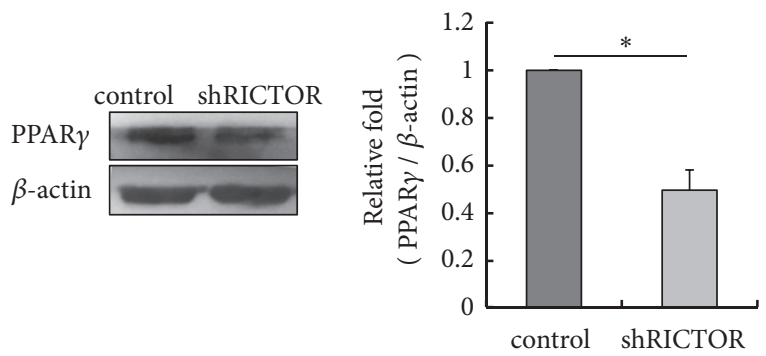

(b)
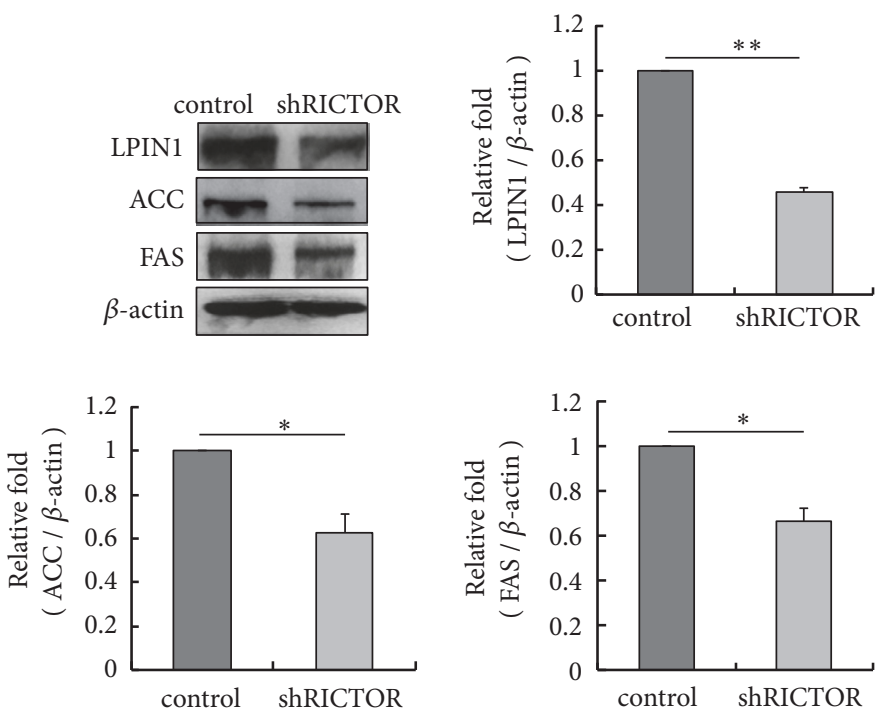

(d)

Figure 5: RICTOR silencing decreases the expression of PPARG and LPIN1, DGAT1, ACACA and FASN in pBMECs. (a) RICTOR silencing decreased PPARG mRNA abundance ( $p=0.023$ ). (b) RICTOR silencing decreased PPAR $\gamma$ protein level. (c) RICTOR silencing decreased the mRNA abundance of LPIN1 ( $p=0.025)$, DGAT1 ( $p=0.017)$, ACACA $(p=0.022)$, and FASN ( $p=0.024)$. (d) RICTOR silencing decreased the protein level of intracellular PPAR $\gamma$, LPIN1, ACC, and FAS. $* p<0.05, * * p<0.01$, ns, no significantly; $\mathrm{n}=3$ biological replicates. Error bars indicate SD.

critical for the expression of PPARG, LPIN1, DGAT1, ACACA, and FASN and the biosynthesis of TAG and FAs. mTORC2 controls lipid synthesis and secretion in pBMECs.

In conclusion, in this study we have examined the function of mTORC2 in lipid biosynthesis and secretion in primary bovine mammary epithelial cells (pBMECs). mTORC2 plays a critical role in regulating lipogenic gene expression, lipogenesis, and secretion in pBMECs, and this process is through PPAR $\gamma$. This finding provides a model by which lipogenesis is regulated in pBMECs.

\section{Data Availability}

The data used to support the findings of this study are included within the article.

\section{Conflicts of Interest}

The authors declare no conflicts of interest.

\section{Authors' Contributions}

Zhixin Guo and Keyu Zhao contributed equally to this work.

\section{Acknowledgments}

The authors thank Dr. Xiao Wang and colleagues in his group for insightful suggestions and technical advice in primary BMECs culture. They thank Ms. Guixiu Liu for generously providing the mammary tissues of Chinese Holstein cows after slaughter in a commercial cattle slaughter farm. They thank Dr. Ying Zhang and Dr. Haiyan Xu for their generous help in GC-MS assay. This work was supported by the Natural Sciences Foundation of China (No. 31760675) and the Science and Technology Major Project of Inner Mongolia Autonomous Region of China to the State Key Laboratory of Reproductive Regulation and Breeding of Grassland Livestock (No. zdzx2018065). 

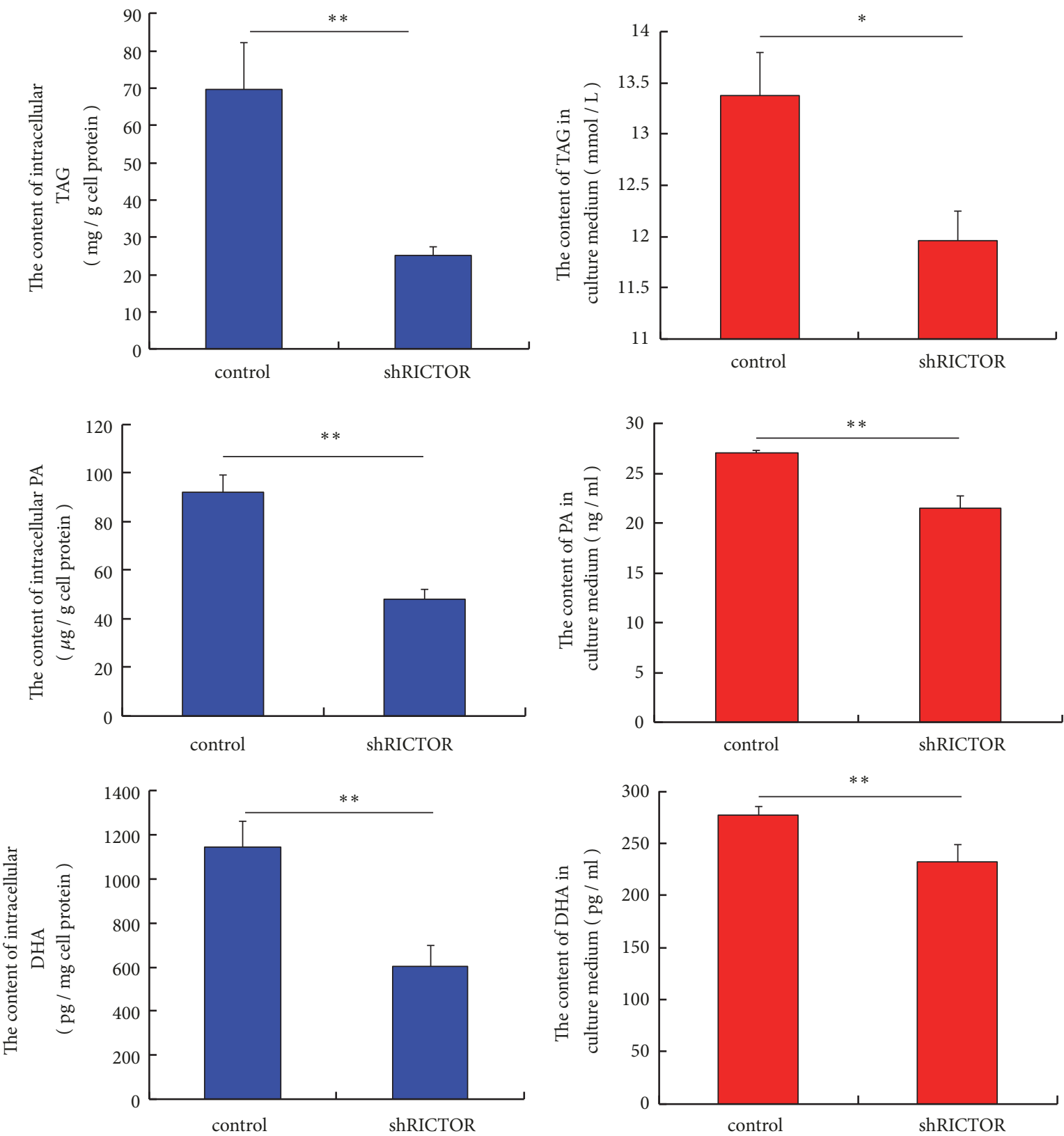

(a)

(b)

FIGURE 6: RICTOR silencing decreases the synthesis and secretion of lipid in pBMECs. (a) RICTOR silencing decreases the intracellular contents of TAG $(p=0.008)$, PA $(p=0.002)$, and DHA $(p=0.007)$. (b) RICTOR silencing decreases the accumulation of TAG ( $p=0.018)$, PA $(p=0.003)$, and DHA $(p=0.01)$ in cell culture medium. $* p<0.05, * * p<0.01$, ns, no significantly; $\mathrm{n}=3$ biological replicates. Error bars indicate $\mathrm{SD}$.

\section{Supplementary Materials}

Supplementary File 1: Isolation and characterization of primary bovine mammary epithelial cells. Table S1: the biomarker genes and primers for PCR. Figure S1: morphology, biomarker genes, and biomarker proteins in primary bovine mammary epithelial cells. (a) Primary bovine mammary epithelial cells isolated by the adherent culture of smallsized cow mammary tissue for 7 days. (b) Purified bovine mammary epithelial cells. (c) Purified bovine mammary fibroblasts. (d) Specific genes transcribed in pBMECs. M: DL2000 Marker; PCR products pg 1: of KRT18 (504 bp); 2: KRT8 (540 bp); and 3: CSN2 (303 bp). (e) KRT7, KRT18, and CSN2 expressed in pBMECs. (f) VIM transcribed, and CSN2 not in bovine mammary fibroblasts. M: DL2000 Marker; PCR products pg 1: of VIM (536 bp); 2: CSN2. (g) VIM expressed, and CSN2 not in bovine mammary fibroblasts. Supplementary File 2. Table S2: the internal control genes and primers 
TABLE 2: Content of 24 types of intracellular fatty acid in control cells and RICTOR-silencing cells (\%).

\begin{tabular}{|c|c|c|}
\hline Fatty acid & Control $^{\mathrm{a}}$ & shRICTOR $^{\mathrm{b}}$ \\
\hline Butyric acid (4:0) & $0.81 \%$ & $0.57 \%(p=1.00)$ \\
\hline Lauric acid (12:0) & $0.19 \%$ & $0.12 \%(p=1.00)$ \\
\hline Myristic acid (14:0) & $1.14 \%$ & $0.28 \%(p=0.22)$ \\
\hline Pentadecanoic acid (15:0) & $0.54 \%$ & $0.08 \%(p=0.25)$ \\
\hline cris-10-Pentadecenoic acid (15:1) & $3.04 \%$ & $0.68 \% * *(p=0.01)$ \\
\hline Palmitic acid (16:0) & $10.33 \%$ & $5.62 \% * *(p=0.01)$ \\
\hline Heptadecanoic acid (17:0) & $1.04 \%$ & $0.39 \%(p=0.45)$ \\
\hline Stearic acid (18:0) & $32.60 \%$ & $19.82 \% * *(p=0.0001)$ \\
\hline Linolelaidic acid (18:2n6t) & $2.05 \%$ & $1.15 \%(p=0.30)$ \\
\hline Linoleic acid (18:2n6c) & $5.39 \%$ & $3.95 \%(p=0.36)$ \\
\hline cis-11-Eicosenoic acid (20:1n9) & $3.89 \%$ & $2.03 \%(p=0.13)$ \\
\hline cis-11,14,17-Eicosatrienoic acid (20:3n3) & $3.38 \%$ & $1.71 \%(p=0.15)$ \\
\hline Eicosapentaenoic acid (20:5n3) & $3.44 \%$ & $2.37 \%(p=0.44)$ \\
\hline Behenic acid (22:0) & $0.95 \%$ & $0.68 \%(p=0.73)$ \\
\hline Erucic acid $(22: \ln 9)$ & $8.79 \%$ & $1.93 \% * *(\mathrm{p}=0.0001)$ \\
\hline cis-13,16-Docosadienoic acid (22:2) & $3.51 \%$ & $2.61 \%(p=0.45)$ \\
\hline Docosahexaenoic acid (22:6n3) & $4.17 \%$ & $2.22 \%(p=0.14)$ \\
\hline Lignoceric acid (24:0) & $0.85 \%$ & $0.50 \%(p=0.69)$ \\
\hline cris-10- Heptadecenoic acid (17:1) & $3.28 \%$ & $4.49 \%(p=0.41)$ \\
\hline cis-11,14-Eicosadienoic acid (20:2) & $2.41 \%$ & $4.31 \%(p=0.14)$ \\
\hline Arachidonic acid (20:4n6) & $4.23 \%$ & $10.39 \% * *(\mathrm{p}=0.0001)$ \\
\hline Henicosanoic acid (21:0) & $0.66 \%$ & $0.84 \%(p=1.00)$ \\
\hline Tricosanoic acid (23:0) & $0.57 \%$ & $0.73 \%(p=1.00)$ \\
\hline Nervonic acid (24:1n9) & $2.76 \%$ & $3.44 \%(p=0.71)$ \\
\hline Total & $100 \%$ & $70.93 \% * *(\mathrm{p}=0.0001)$ \\
\hline
\end{tabular}

a: content of product in control group/total content in control group $\times 100 \%$.

b: content of product in RICTOR-silencing group/total content in control group $\times 100 \%$.

shRICTOR: RICTOR-silencing $(* * p<0.01)$.

for qPCR. Figure S2: RICTOR knocked down using targeting shRNA. (a) Control cells. (b) pRNAT-U6.1/Neo-RICTORshRNA-transfected pBMECs expressing the green fluorescent protein (EGFP). Scale bar: 200 px. (c) RNA integrity assessed via electrophoresis. Total RNA was isolated from control cells and RICTOR silencing cells, respectively. RNA quantity of control cells was $883.5 \mathrm{ng} / \mu \mathrm{L}$, and the RICTOR silencing cells were $683.4 \mathrm{ng} / \mu \mathrm{L}$. The RNA stock solution was diluted 10 times and then taken $2 \mu \mathrm{L}$ for electrophoresis. Total RNAs pg M: DL2000 Marker; 1: of control cells; 2: RICTOR silencing cells. (Supplementary Materials)

\section{References}

[1] R. G. Jensen, A. M. Ferris, and C. J. Lammi-Keefe, "The composition of milk fat," Journal of Dairy Science, vol. 74, no. 9, pp. 3228-3243, 1991.

[2] J. B. German and C. J. Dillard, "Composition, structure and absorption of milk lipids: A source of energy, fatsoluble nutrients, and bioactive molecules," Critical Reviews in Food Science and Nutrition, vol. 46, no. 9, pp. 57-92, 2006.

[3] J. S. Osorio, J. Lohakare, and M. Bionaz, "Biosynthesis of milk fat, protein, and lactose: Roles of transcriptional and posttranscriptional regulation," Physiological Genomics, vol. 48, no. 4, pp. 231-256, 2016.
[4] H. Shi, W. Zhao, C. Zhang, K. Shahzad, J. Luo, and J. J. Loor, "Transcriptome-wide analysis reveals the role of PPAR $\gamma$ controlling the lipid metabolism in goat mammary epithelial cells," PPAR Research, vol. 2016, Article ID 9195680, 11 pages, 2016.

[5] M. Bionaz, S. Chen, M. J. Khan, and J. J. Loor, "Functional role of PPARs in ruminants: Potential targets for fine-tuning metabolism during growth and lactation," PPAR Research, vol. 2013, Article ID 684159, 28 pages, 2013.

[6] A. K. G. Kadegowda, M. Bionaz, L. S. Piperova, R. A. Erdman, and J. J. Loor, "Peroxisome proliferator-activated receptor- $\gamma$ activation and long-chain fatty acids alter lipogenic gene networks in bovine mammary epithelial cells to various extents," Journal of Dairy Science, vol. 92, no. 9, pp. 4276-4289, 2009.

[7] K. V. Ruggles, A. Turkish, and S. L. Sturley, "Making, baking, and breaking: The synthesis, storage, and hydrolysis of neutral lipids," Annual Review of Nutrition, vol. 33, pp. 413-451, 2013.

[8] Y. Zeng, C. Wang, Y. Niu et al., "The influence of delipidation on triglyceride and LIPIN 1 of porcine embryos derived from parthenogenetic activation," Reproduction in Domestic Animals, vol. 52, no. 5, pp. 842-850, 2017.

[9] G. Lee, Y. Zheng, S. Cho et al., "Post-transcriptional Regulation of De Novo Lipogenesis by mTORC1-S6K1-SRPK2 Signaling," Cell, vol. 171, no. 7, pp. 1545-1558, 2017.

[10] M. Bionaz and J. J. Loor, "Gene networks driving bovine milk fat synthesis during the lactation cycle," BMC Genomics, vol. 9, pp. 366-368, 2008. 
[11] R. A. Saxton and D. M. Sabatini, "mTOR signaling in growth, metabolism, and disease," Cell, vol. 168, no. 6, pp. 960-976, 2017.

[12] K. Düvel, J. L. Yecies, S. Menon et al., "Activation of a metabolic gene regulatory network downstream of mTOR complex 1," Molecular Cell, vol. 39, no. 2, pp. 171-183, 2010.

[13] I. J. Lodhi, X. Wei, and C. F. Semenkovich, "Lipoexpediency: De novo lipogenesis as a metabolic signal transmitter," Trends in Endocrinology \& Metabolism, vol. 22, no. 1, pp. 1-8, 2011.

[14] D. W. Lamming and D. M. Sabatini, "A central role for mTOR in lipid homeostasis," Cell Metabolism, vol. 18, no. 4, pp. 465-469, 2013.

[15] D. D. Sarbassov, D. A. Guertin, S. M. Ali, and D. M. Sabatini, "Phosphorylation and regulation of Akt/PKB by the rictormTOR complex," Science, vol. 307, no. 5712, pp. 1098-1101, 2005.

[16] S. J. Bulley, A. Droubi, J. H. Clarke et al., "In B cells, phosphatidylinositol 5-phosphate 4-kinase- $\alpha$ synthesizes PI(4,5)P2 to impact mTORC2 and Akt signaling," Proceedings of the National Academy of Sciences of the United States of America, vol. 113, no. 38, pp. 10571-10576, 2016.

[17] A. Hagiwara, M. Cornu, N. Cybulski et al., "Hepatic mTORC2 activates glycolysis and lipogenesis through Akt, glucokinase, and SREBP1c," Cell Metabolism, vol. 15, no. 5, pp. 725-738, 2012.

[18] C.-M. Hung, C. M. Calejman, J. Sanchez-Gurmaches et al., "Rictor/mTORC2 Loss in the Myf5-lineage reprograms brown fat metabolism and protects mice against obesity and metabolic disease," Cell Reports, vol. 8, no. 1, pp. 256-271, 2014.

[19] X. Wang, L. Xiu, Q. Hu et al., "Deep sequencing-based transcriptional analysis of bovine mammary epithelial cells gene expression in response to in vitro infection with staphylococcus aureus stains," PLoS ONE, vol. 8, no. 12, p. e82117, 2013.

[20] Z. Guo, Y. Wang, X. Feng et al., "Rapamycin inhibits expression of elongation of very-long-chain fatty acids 1 and synthesis of docosahexaenoic acid in bovine mammary epithelial cells," Asian-Australasian Journal of Animal Sciences, vol. 29, no. 11, pp. 1646-1652, 2016.

[21] X. Feng, L. Bao, M. Wu et al., "Inhibition of ERK1/2 downregulates triglyceride and palmitic acid accumulation in cashmere goat foetal fibroblasts," Journal of Applied Animal Research, vol. 46, no. 1, pp. 1185-1192, 2018.

[22] Y. Wang, Z. Guo, M. Liu et al., "Proteasome subunit beta type 1 interacts directly with Rheb and regulates the cell cycle in Cashmere goat fetal fibroblasts," Animal Cells and Systems, vol. 5, no. 21, pp. 307-315, 2017.

[23] C. L. Andersen, J. L. Jensen, and T. F. Ørntoft, "Normalization of real-time quantitative reverse transcription-PCR data: a modelbased variance estimation approach to identify genes suited for normalization, applied to bladder and colon cancer data sets," Cancer Research, vol. 64, no. 15, pp. 5245-5250, 2004.

[24] C. M. Chresta, B. R. Davies, I. Hickson et al., "AZD8055 is a potent, selective, and orally bioavailable ATP-competitive mammalian target of rapamycin kinase inhibitor with in vitro and in vivo antitumor activity," Cancer Research, vol. 70, no. 1, pp. 288-298, 2009.

[25] M. Yuan, E. Pino, L. Wu, M. Kacergis, and A. A. Soukas, "Identification of Akt-independent regulation of hepatic lipogenesis by mammalian target of rapamycin (mTOR) complex 2," The Journal of Biological Chemistry, vol. 287, no. 35, pp. 2957929588, 2012.

[26] S. Li, Y.-T. Oh, P. Yue, F. R. Khuri, and S.-Y. Sun, "Inhibition of mTOR complex 2 induces GSK3/FBXW7-dependent degradation of sterol regulatory element-binding protein 1 (SREBP1) and suppresses lipogenesis in cancer cells," Oncogene, vol. 35, no. 5, pp. 642-650, 2016.

[27] M. Jiang, J. N. Lee, M. Bionaz, X. Y. Deng, Y. Wang, and T. Seagroves, "Evaluation of suitable internal control genes for RTqPCR in yak mammary tissue during the lactation cycle," PLoS ONE, vol. 11, no. 1, p. e0147705, 2016.

[28] S. A. Bustin, V. Benes, J. A. Garson et al., “The MIQE guidelines: minimum information for publication of quantitative real-time PCR experiments," Clinical Chemistry, vol. 55, no. 4, pp. 611-622, 2009.

[29] J. R. Chapman and J. Waldenström, "With reference to reference genes: a systematic review of endogenous controls in gene expression studies," PLoS ONE, vol. 10, no. 11, p. e0141853, 2015.

[30] L. Wang, Y. Lin, Y. Bian et al., "Leucyl-tRNA synthetase regulates lactation and cell proliferation via mTOR signaling in dairy cow mammary epithelial cells," International Journal of Molecular Sciences, vol. 15, no. 4, pp. 5952-5969, 2014.

[31] X. Zhang, F. Zhao, Y. Si et al., "GSK3 $\beta$ regulates milk synthesis in and proliferation of dairy cow mammary epithelial cells via the mTOR/S6K1 signaling pathway," Molecules, vol. 19, no. 7, pp. 9435-9452, 2014.

[32] M. Wang, Z. Wang, C. Yang, L. Liu, and N. Jiang, "Protein 14$3-3 \varepsilon$ regulates cell proliferation and casein synthesis via PI3KmTOR pathway in dairy cow mammary epithelial cells," Journal of Agricultural and Food Chemistry, vol. 66, no. 45, pp. 1200012008, 2018.

[33] Y. Cui, Z. Liu, X. Sun et al., "Thyroid hormone responsive protein spot 14 enhances lipogenesis in bovine mammary epithelial cells," In Vitro Cellular \& Developmental Biology Animal, vol. 51, no. 6, pp. 586-594, 2015.

[34] H. F. Xu, J. Luo, W. S. Zhao et al., "Overexpression of SREBP1 (sterol regulatory element binding protein 1) promotes de novo fatty acid synthesis and triacylglycerol accumulation in goat mammary epithelial cells," Journal of Dairy Science, vol. 99, no. 1, pp. 783-795, 2016.

[35] D. Yao, J. Luo, Q. He et al., "SCD1 alters long-chain fatty acid (LCFA) composition and its expression is directly regulated by SREBP-1 and PPAR $\gamma 1$ in dairy goat mammary cells," Journal of Cellular Physiology, vol. 232, no. 3, pp. 635-649, 2017. 


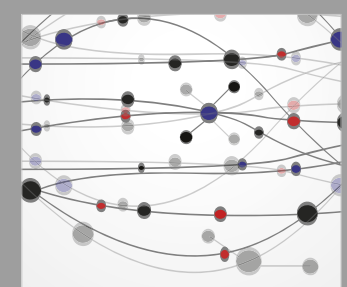

The Scientific World Journal
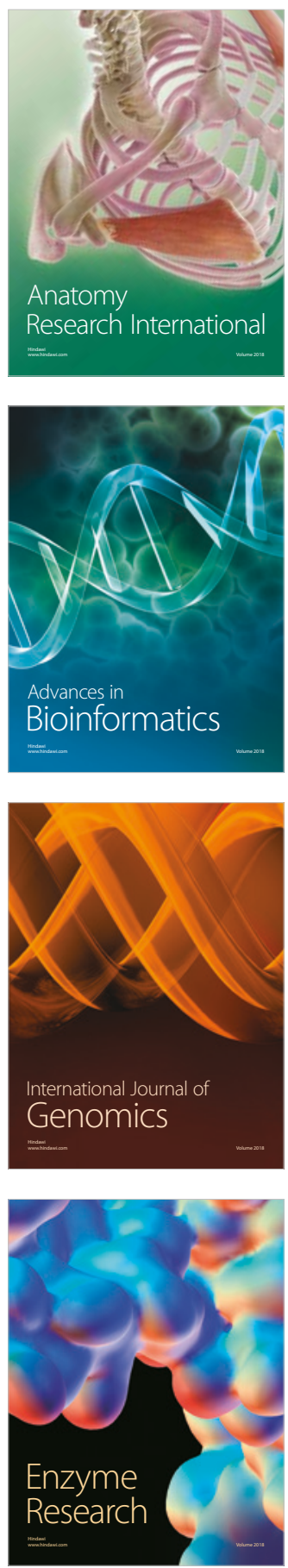
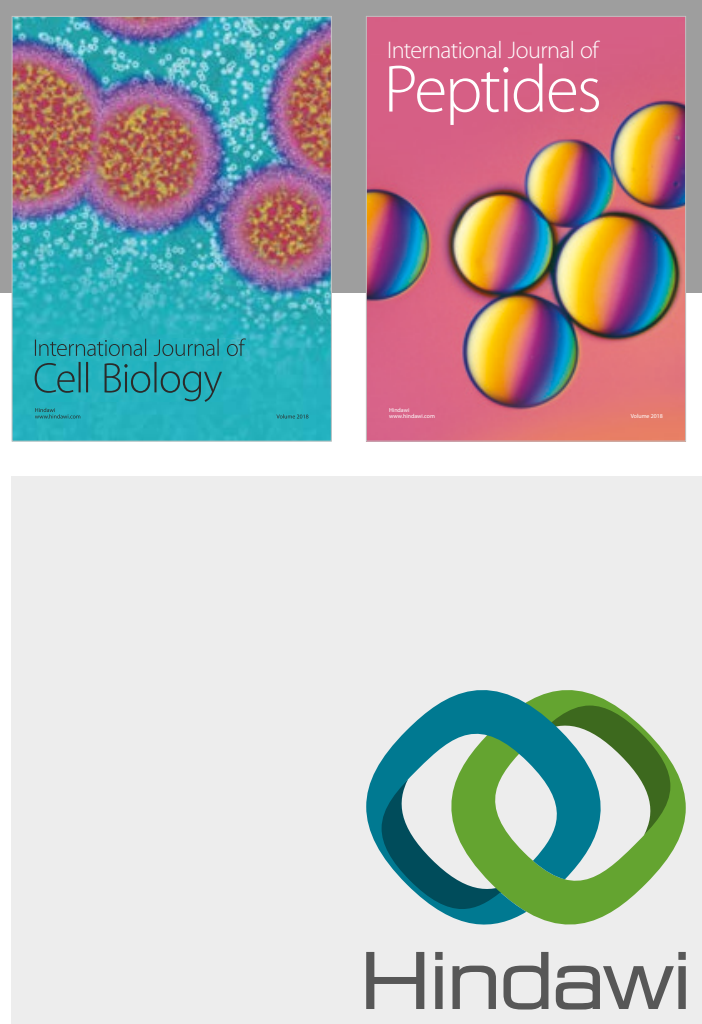

Submit your manuscripts at

www.hindawi.com
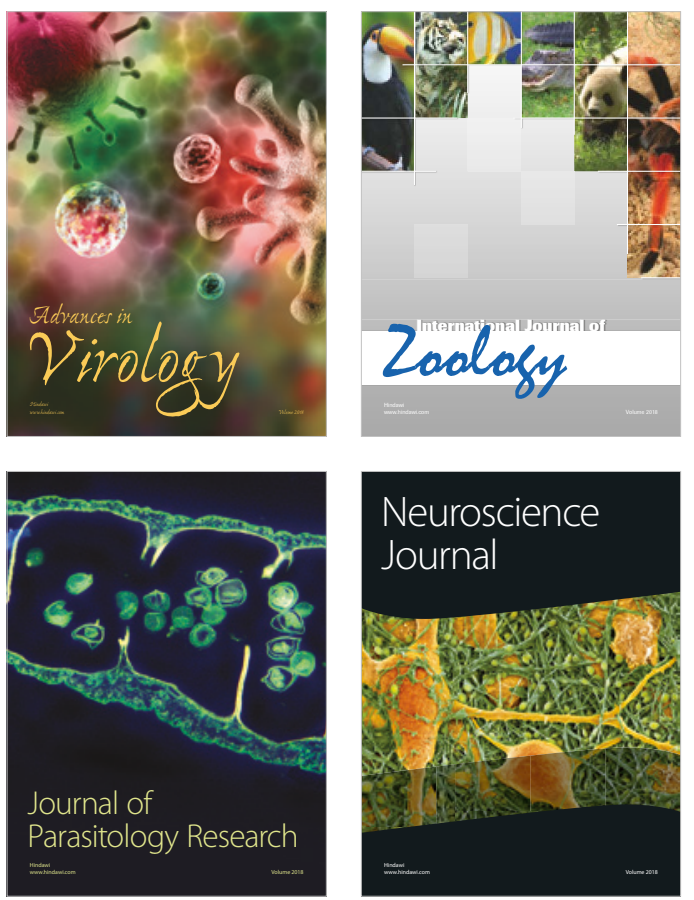
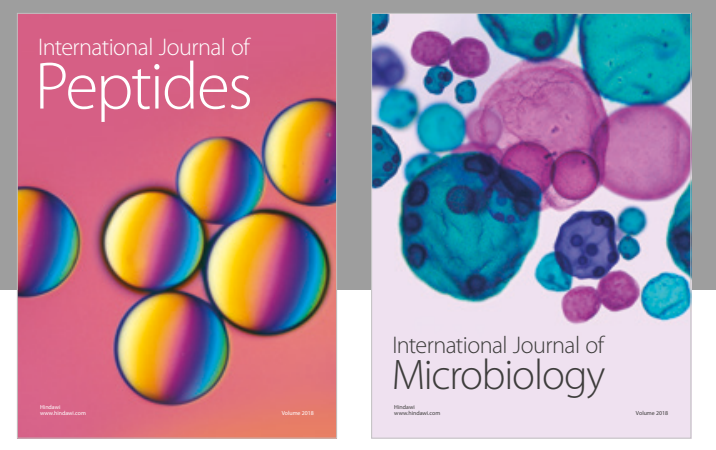

nternational Journal of Microbiology
Journal of
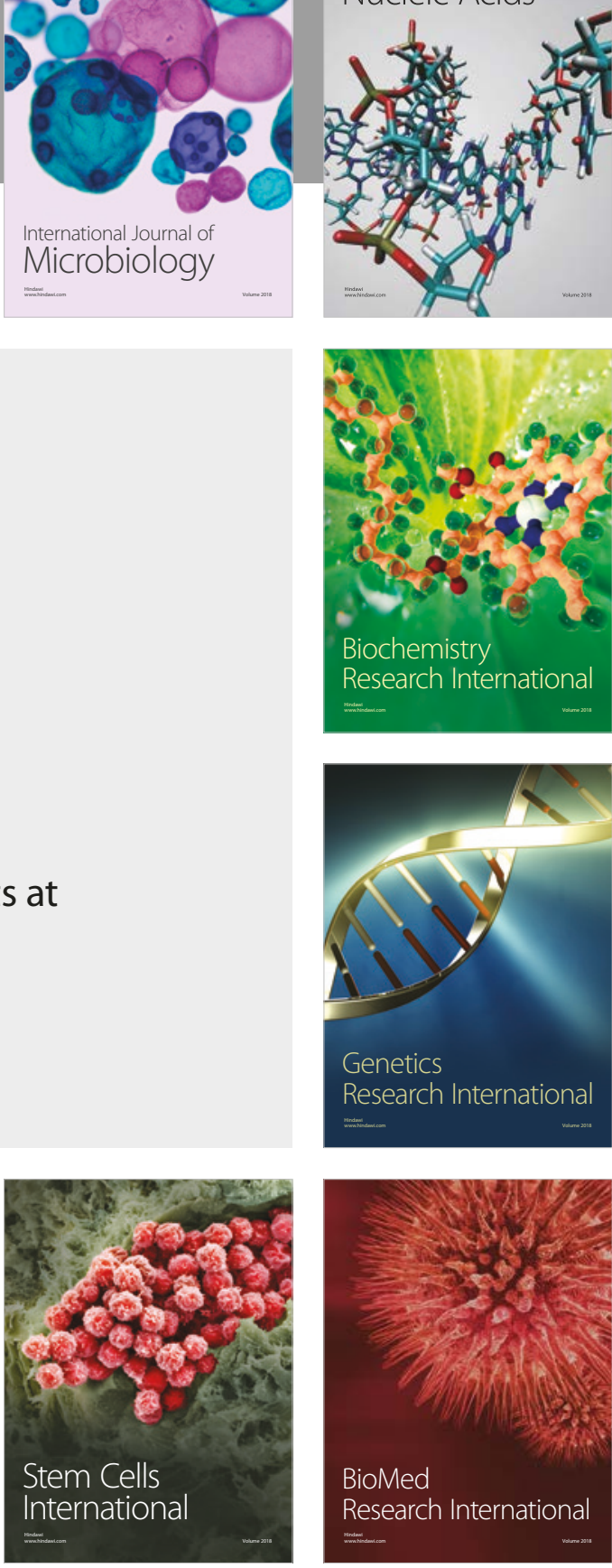
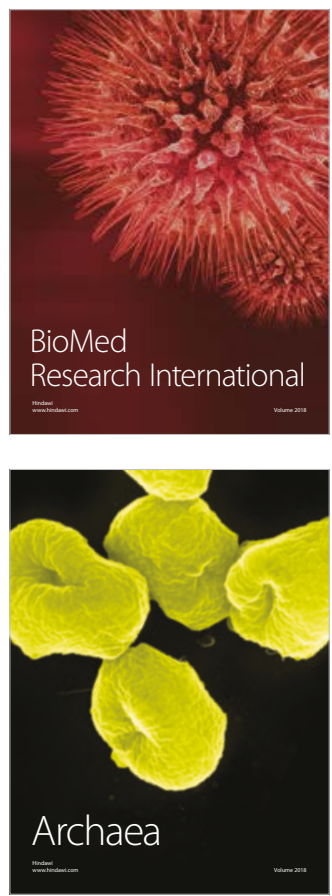